\title{
Comunidade bacteriana como indicadora do efeito de feijoeiro geneticamente modificado sobre organismos não alvo
}

\author{
Adriano Moreira Knupp ${ }^{(1)}$, Claudia Miranda Martins(2), Josias Corrêa de Faria(1), \\ Norma Gouvêa Rumjanek ${ }^{(3)}$ e Gustavo Ribeiro Xavier ${ }^{(3)}$
}

\begin{abstract}
(1)Embrapa Arroz e Feijão, Caixa Postal 179, CEP 75375-000 Santo Antônio de Goiás, GO. E-mail: adrianoknupp@cnpaf.embrapa.br, josias@cnpaf.embrapa.br (2)Universidade Federal do Ceará, Campus do Pici, CEP 60455-760 Fortaleza, CE. E-mail: claudia.miranda.martins@gmail.com ${ }^{(3)}$ Embrapa Agrobiologia, Rodovia BR 465, Km 7, CEP $23890-000$ Seropédica, RJ. E-mail: norma@cnpab.embrapa.br, gustavo@cnpab.embrapa.br
\end{abstract}

Resumo - O objetivo deste trabalho foi avaliar o efeito do feijoeiro geneticamente modificado quanto à resistência ao Bean Golden Mosaic Virus, BGMV (Olathe M1-4), sobre organismos não alvo. De um experimento implantado no campo, em delineamento inteiramente casualizado, com dois tratamentos (Olathe Pinto e evento elite Olathe M1-4), dois períodos amostrais (estádio V4 e R6) e dez repetições, obtiveram-se células bacterianas cultivadas e não cultivadas da rizosfera e do solo não rizosférico, para as quais se procedeu à extração de DNA total. A região V6-V8 do 16S rDNA foi amplificada para a comunidade bacteriana total, e também realizou-se amplificação com iniciadores específicos para o subgrupo alfa $(\alpha)$ do filo Proteobacteria a partir de células não cultivadas. Foram obtidos dendrogramas comparativos entre a variedade Olathe Pinto (convencional) e o evento elite Olathe M1-4 (geneticamente modificado) utilizando-se o coeficiente de Jaccard e o método UPGMA (Unweighted pair-group method with arithmetic mean). Os agrupamentos obtidos dos perfis de 16S rDNA PCR-DGGE indicam alterações na comunidade bacteriana da rizosfera em função da transformação das plantas são mais notáveis nos perfis obtidos para alfa-proteobacteria. A origem das amostras e o estágio de desenvolvimento das plantas afetam a comunidade bacteriana.

Termos para indexação: Phaseolus vulgaris, biossegurança, DGGE, impacto ambiental, organismos não alvo, transgênico.

\section{Bacterial community as an indicator of genetically modified common bean effect on nontarget organisms}

\begin{abstract}
The objective of this work was to evaluate the effect of genetically modified common bean for Bean Golden Mosaic Virus, BGMV, resistance (Olathe M1-4) on nontarget organisms. In a field experiment established in a completely randomized design with two treatments (Olathe Pinto cultivar and M1-4 Olathe elite event), two sampling periods (V4 and R6 stages) and ten replicates, cultivated and non-cultivated bacterial cells from rhizosphere soil and bulk soil were obtained, and their total DNA was extracted. The V6-V8 region of 16S rDNA was amplified for the whole bacterial community, and primers specific for the alpha $(\alpha)$ subgroup of the Proteobacteria phylum were obtained from uncultured cells and used for amplification. Using the Jaccard coefficient and UPGMA (Unweighted pair-group method with arithmetic mean), dendrograms comparing the conventional Olathe Pinto and the elite event Olathe M1-4 transgenic varieties were obtained. The clusters obtained from the 16S rDNA PCR-DGGE profiles indicate changes in the rhizosphere bacterial community in genetically modified plants, being more notable in the profiles obtained for alphaproteobacteria. Sample origin and plant development stages affect bacterial community profiles.
\end{abstract}

Index terms: Phaseolus vulgaris, biosafety, DGGE, environmental impact, nontarget organisms, transgenic.

\section{Introdução}

Entre as doenças do feijoeiro, uma das mais agressivas é o mosaico-dourado, causado pelo Bean Golden Mosaic Virus (BGMV), encontrado em todas as regiões de cultivo, que pode levar a perdas de 40 a $100 \%$ da lavoura (Bonfim et al., 2007). A doença é causada por um geminivírus que tem como vetor a mosca-branca (Bemisia tabaci Gennadius). Algumas formas de controle da mosca-branca, tais como seleção de genótipos resistentes (Oriani, 1998), controle biológico (Stansly et al., 2004) e controle químico (Torres \& Silva-Torres, 2008) têm sido descritas para diversos cultivos. No entanto, nenhuma

Pesq. agropec. bras., Brasília, v.44, n.12, p.1692-1699, dez. 2009 
medida isolada é eficaz no controle da doença, e ainda não existe nenhum genótipo com imunidade completa para o BGMV no gênero Phaseolus (Faria et al., 2006).

Um dos receios do uso da tecnologia do DNA recombinante, base para a transformação genética de plantas, está nos possíveis efeitos da inserção de uma planta geneticamente modificada sobre organismos não alvo. Desse modo, em virtude da íntima interação entre os microrganismos associados às raízes das plantas, mediada por reconhecimento de exsudados radiculares e por sinalizações moleculares (Wasaki et al., 2005), são necessários estudos sobre os possíveis efeitos do uso de plantas geneticamente modificadas sobre essas interações. O uso da técnica de 16S rDNA PCR-DGGE tem se mostrado eficiente no diagnóstico de alterações da comunidade bacteriana associada à rizosfera de plantas (Ferreira et al., 2008, 2009; Zilli et al., 2008).

O objetivo deste trabalho foi avaliar o efeito de plantas geneticamente modificadas de feijoeiro quanto à resistência ao BGMV sobre a comunidade bacteriana da rizosfera das plantas transformadas em comparação à das plantas convencionais, não transformadas.

\section{Material e Métodos}

O estudo foi realizado com amostras do solo agregado às raízes e de células bacterianas da rizosfera das plantas avaliadas, coletadas de um experimento implantado em 9 de março de 2006 na Embrapa Arroz e Feijão, no Município de Santo Antônio de Goiás, GO, em uma área experimental com histórico de plantio convencional de feijoeiro $\left(16^{\circ} 30^{\prime} 24^{\prime \prime} \mathrm{S}, 4^{\circ} 16^{\prime} 52^{\prime \prime} \mathrm{W}\right)$. O evento transgênico utilizado no presente trabalho foi descrito por Faria et al. (2006).

O feijoeiro foi cultivado em Latossolo Vermelho distrófico argiloso (460 $\mathrm{g} \mathrm{kg}^{-1}$ de argila, $120 \mathrm{~g} \mathrm{~kg}^{-1} \mathrm{de}$ silte e $420 \mathrm{~g} \mathrm{~kg}^{-1}$ de areia). A análise química do solo da camada $0-20 \mathrm{~cm}$ de profundidade indicou: $\mathrm{pH}$ em água, 5,9; MO, $20 \mathrm{~g} \mathrm{~kg}^{-1}$; P (Mehlich 1), 5,5 $\mathrm{mg} \mathrm{dm}^{-3}$; $\mathrm{K}$ (Mehlich 1), $61 \mathrm{mg} \mathrm{dm}^{-3} ; \mathrm{Ca}, 2,1 \mathrm{cmol}_{\mathrm{c}} \mathrm{dm}^{-3} ; \mathrm{Mg}$, $1,1 \mathrm{cmol}_{\mathrm{c}} \mathrm{dm}^{-3} ; \mathrm{Al}, 0,0 \mathrm{cmol}_{\mathrm{c}} \mathrm{dm}^{-3} ; \mathrm{H}+\mathrm{Al}, 4,53 \mathrm{cmol}_{\mathrm{c}}$ $\mathrm{dm}^{-3}$. O experimento foi instalado em delineamento inteiramente casualizado, com dois tratamentos e dez repetições, num total de 20 parcelas, cada uma com cinco fileiras de plantas de $5 \mathrm{~m}$ cada uma, $1 \mathrm{~m}$ entre as fileiras e com o vírus inoculado em linhas de feijoeiro entre as parcelas. Foram avaliados a variedade Olathe Pinto e o evento elite Olathe M1-4. Para garantir a identidade das plantas geneticamente modificadas, as parcelas ocupadas com o genótipo Olathe M1-4 receberam, dez dias após o plantio (DAP), uma subdose $\left(1,2 \mathrm{~mL} \mathrm{~L}^{-1}\right)$ do herbicida Finale (glufosinato de amônio). A planta transformada tem o gene bar para resistência ao herbicida, que serviu como marcador da transformação genética (Aragão et al., 2001).

As coletas foram realizadas aos 26 e 40 DAP, correspondentes aos estádios V4 e R6 do feijoeiro (Fernández et al., 1986). As plantas com o solo agregado às raízes foram coletadas da terceira linha, que caracterizou o centro da parcela, de cinco linhas. Amostras de $1 \mathrm{~g}$ de solo rizosférico foram coletadas e agitadas a $175 \mathrm{rpm}$ por $30 \mathrm{~min}$ em $20 \mathrm{~mL}$ de $\mathrm{NaCl}(0,85 \%)$. Dessa suspensão, uma alíquota foi inoculada em meios de cultura TY (Döbereiner et al., 1999) e KB (Geels $\&$ Schippers, 1983) e mantida em estufa a $28^{\circ} \mathrm{C}$, por quatro dias, para a obtenção da fração cultivável; outra alíquota, para a fração não cultivável, foi centrifugada a $2.400 \mathrm{~g}$ por $30 \mathrm{~min}$, a $4^{\circ} \mathrm{C}$. Ambas as frações foram ressuspensas em água deionizada estéril $(1 \mathrm{~mL})$, e a extração do DNA foi feita de acordo com Xavier et al. (2004). Para as amostras de solo não rizosférico, a extração foi realizada com o kit MoBio (Ultra Clean Soil DNA, MoBio Laboratories Inc., Califórnia, EUA), de acordo com o procedimento do fabricante. O DNA extraído foi adicionalmente purificado utilizando o kit Wizard (Promega, Madison, EUA), de acordo com as especificações do fabricante.

Os iniciadores 968F (5'AACGCGAAGAACCTTAC3') com grampo GC (5'CGCCCCCGCGCGCGGCGGGCGGGGCGGGGGCACGGGGGG3') e 1401R (5'GCGTGTGTACAAGACCC3'), específicos para a região $16 \mathrm{~S}$ do rDNA correspondente à região variável V6-V8 (Nübel et al., 1996), foram utilizados para amplificação das amostras correspondentes à comunidade bacteriana rizosférica. As reações foram preparadas em volume final de $35 \mu \mathrm{L}$, e consistiram de $50 \mathrm{ng}$ de DNA, tampão $\left(10 \mathrm{mmol} \mathrm{L}^{-1}\right)$, $\mathrm{MgCl}_{2} \quad\left(3,5 \mathrm{mmol} \mathrm{L}^{-1}\right)$, dNTP $\left(0,2 \mathrm{mmol} \mathrm{L}^{-1}\right.$ de cada base), BSA $\left(0,5 \mathrm{ng} \mathrm{mL}^{-1}\right)$, Taq DNA polimerase ( $1 \mathrm{U}$ - Invitrogen, Brasil) e $0,2 \mu \mathrm{mol} \mathrm{L} \mathrm{L}^{-1}$ de cada iniciador. As condições da reação de PCR seguiram o procedimento descrito por Gelsomino et al. (1999). 
A amplificação para o subgrupo alfa $(\alpha)$ do filo Proteobacteria foi realizada com os iniciadores F203 (5'CCGCATACGCCCTACGGGGGAAAGATTTAT3'), proposto por Gomes et al. (2001), e R1494 (5'CTACGG(T/C)TACCTTGTTACGAC3'), proposto por Weisburg et al. (1991). Após diluição do DNA total (1:10), foi preparada uma solução para reação de PCR que consistiu num volume final de $25 \mu \mathrm{L}$, contendo $1 \mu \mathrm{L}$ da diluição do DNA, tampão (10 mmol L ${ }^{-1}$ de Tris-HCl, pH 8,4; $10 \mathrm{mmol} \mathrm{L}^{-1}$ de $\left.\mathrm{KCl}\right), \mathrm{MgCl}_{2}\left(3,5 \mathrm{mmol} \mathrm{L}^{-1}\right)$, dNTP (0,2 mmol L-1 de cada base), BSA $\left(0,5 \mathrm{ng} \mathrm{mL}^{-1}\right)$, 1,4 U de Taq DNA polimerase e $200 \mathrm{mmol} \mathrm{L}^{-1} \mathrm{de}$ cada iniciador (203-F e 1494-R, Alpha DNA, Montreal, Quebec, Canadá). As condições de PCR foram: aquecimento inicial $\left(94^{\circ} \mathrm{C}, 5 \mathrm{~min}\right) ; 20$ ciclos compostos por desnaturação $\left(94^{\circ} \mathrm{C}, 1 \mathrm{~min}\right)$; anelamento $\left(56^{\circ} \mathrm{C}, 1 \mathrm{~min}\right)$; extensão $\left(72^{\circ} \mathrm{C}, 2 \mathrm{~min}\right)$, e uma etapa final de extensão $\left(72^{\circ} \mathrm{C}, 10 \mathrm{~min}\right)$. A partir do produto amplificado na etapa anterior, foi realizada uma diluição 1:25 e uma nova reação foi preparada com um volume final de $35 \mu \mathrm{L}$ sem BSA, com $1 \mu \mathrm{L}$ da diluição do material amplificado e os iniciadores F968-GC e R1401R. As condições de PCR foram as mesmas utilizadas
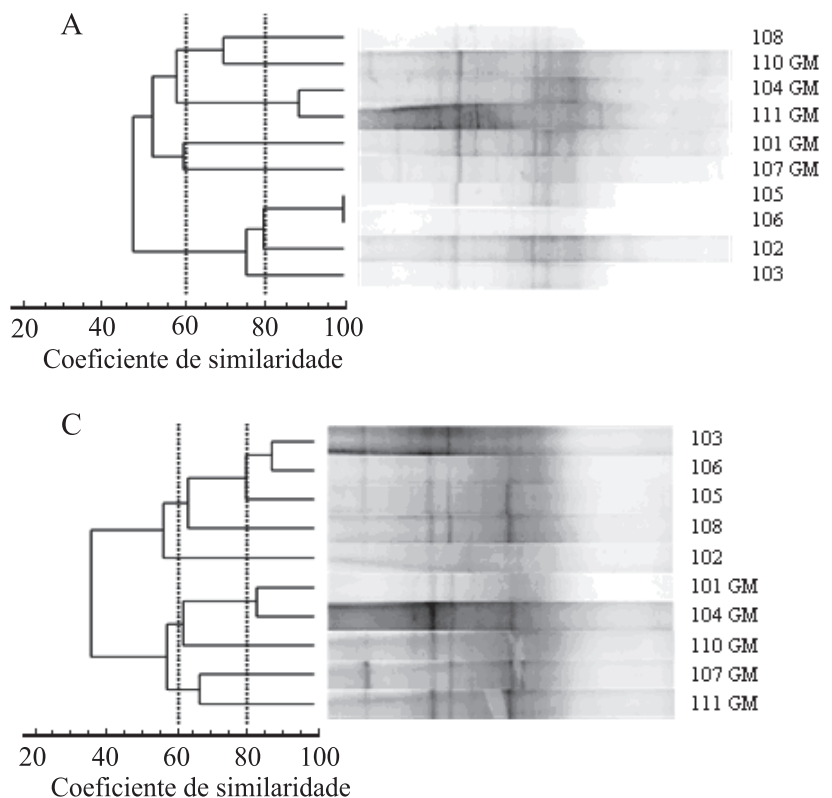

para amplificação da região V6-V8 com apenas 20 ciclos de desnaturação, de acordo com Gomes et al. (2001).

Dos produtos de PCR, $15 \mu \mathrm{L}$ foram aplicados em gel desnaturante de poliacrilamida $6 \%(\mathrm{~N}$-acrilamida, N-metilbisacrilamida, 37:1) dissolvido em tampão TAE 0,5X (Tris-base, $20 \mathrm{mmol} \mathrm{L}^{-1}, \mathrm{pH} \mathrm{7,8}$; acetato de sódio, $10 \mathrm{mmol} \mathrm{L}^{-1}$ e Na-EDTA, 0,5 mmol L-1). $O$ gradiente de desnaturante químico $(45-65 \%)$ foi obtido usando-se duas soluções, uma contendo apenas solução de poliacrilamida e outra contendo ureia $\left(7 \mathrm{~mol} \mathrm{~L}^{-1}\right)$, formamida $(40 \%, \mathrm{v} / \mathrm{v})$ e poliacrilamida. A eletroforese foi realizada no sistema Dcode Systems (Bio-Rad, Hercules, EUA) sob voltagem de $120 \mathrm{~V}\left(60^{\circ} \mathrm{C}\right)$ durante 16 horas. Como marcador para normalização dos géis, utilizou-se uma amostra formada pela mistura da amplificação do DNA dos microrganismos Sinorhizobium fredii (estirpe BR 112), Azospirillum brasiliense (estirpe BR11001), Burkholderia sp. (estirpe BR11340), Rhizobium tropici (estirpe BR10016), obtidos da Embrapa Agrobiologia. Ao final, o gel foi corado com uma solução de nitrato de prata, como descrito por Creste et al. (2001).
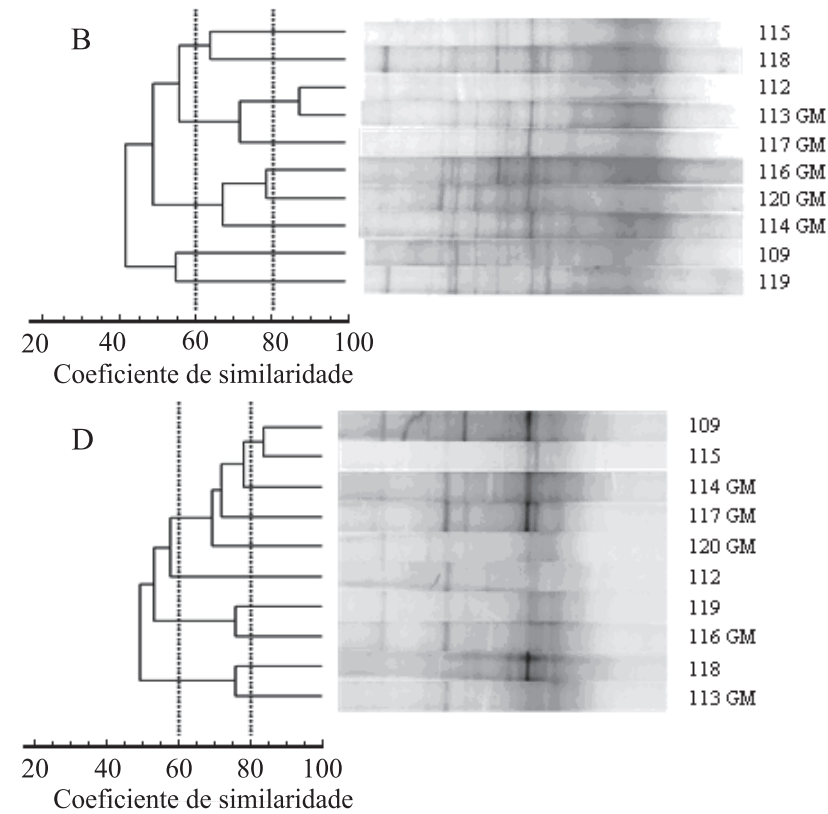

Figura 1. Agrupamentos das amostras obtidas por 16S rDNA PCR-DGGE a partir de células bacterianas rizosféricas. Números seguidos pelas letras GM correspondem às parcelas de plantas geneticamente modificadas e números sem letra, às parcelas convencionais. A e $\mathrm{B}$, coleta 1 (estádio V4); C e D, coleta 2 (estádio R6). Dendrogramas gerados pelo programa GelCompar II, com o coeficiente de Jaccard pelo método UPGMA.

Pesq. agropec. bras., Brasília, v.44, n.12, p.1692-1699, dez. 2009 
As imagens dos géis foram digitalizadas com scanner Genius Color Page HR7X Slim (KYE International Corp, Miami, EUA), e os dendrogramas foram obtidos pelo programa GelCompar II versão 3 (Applied Maths, EUA) utilizando-se o coeficiente de Jaccard e o método de agrupamento UPGMA (Unweighted pair-group method with arithmetic mean).

\section{Resultados e Discussão}

A partir dos dendrogramas (Figuras 1 a 3 ) gerados para as diferentes formas de obtenção de células bacterianas e para o subgrupo alfa $(\alpha)$ do filo Proteobacteria, foram construídas tabelas destacando os agrupamentos formados com valores
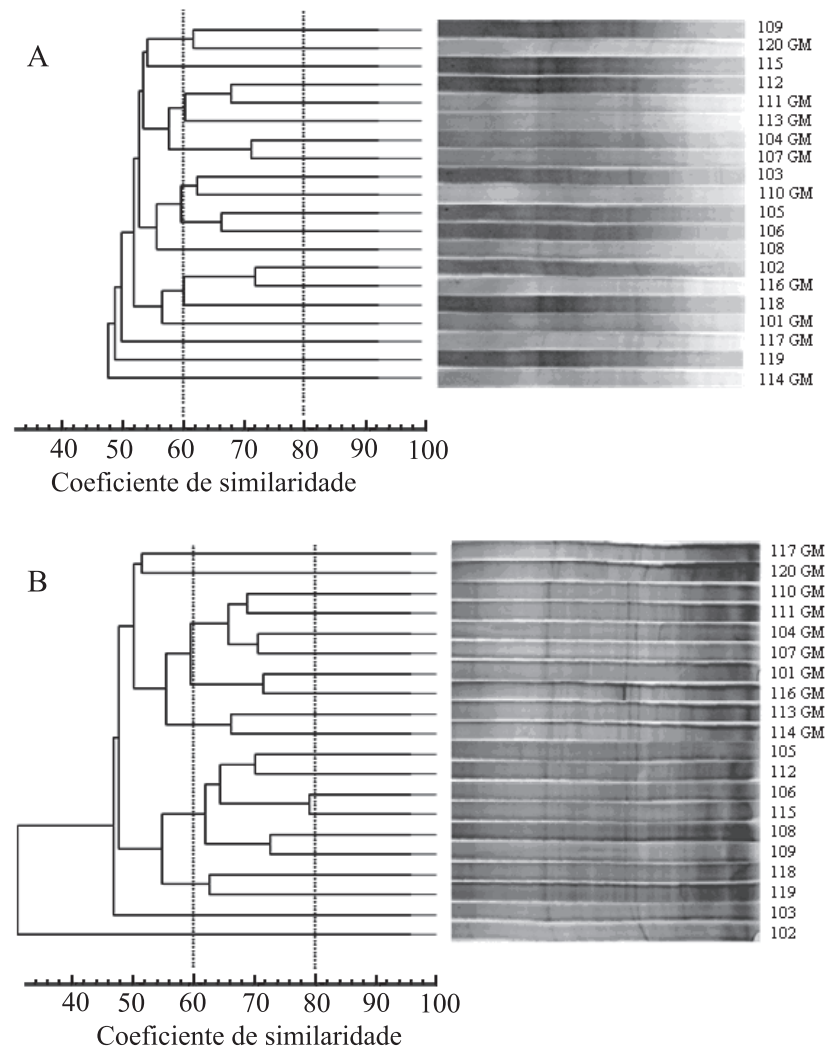

Figura 2. Agrupamentos das amostras de perfis bacterianos obtidos por $16 \mathrm{~S}$ rDNA PCR-DGGE da comunidade bacteriana não rizosférica de plantas convencionais (nº de parcela sem letra) e geneticamente modificadas (número de parcela seguido pela letra GM. A, primeira coleta, estádio V4 (26 DAP); B, segunda coleta, estádio R6 (40 DAP). Dendrogramas gerados pelo programa GelCompar II, com o coeficiente de Jaccard e o método UPGMA. de similaridade iguais ou superiores a 60 e $80 \%$ (Tabelas 1 e 2). Apesar de alguns agrupamentos, nas diferentes formas de obtenção de células, separarem amostras obtidas de plantas geneticamente modificadas das convencionais, esse efeito não se manteve ao longo dos períodos avaliados aos 26 (Tabela 1) e 40 dias (Tabela 2) após o plantio, além de diminuir à medida que as observações para similaridade de $80 \%$ ou superior se restringem.
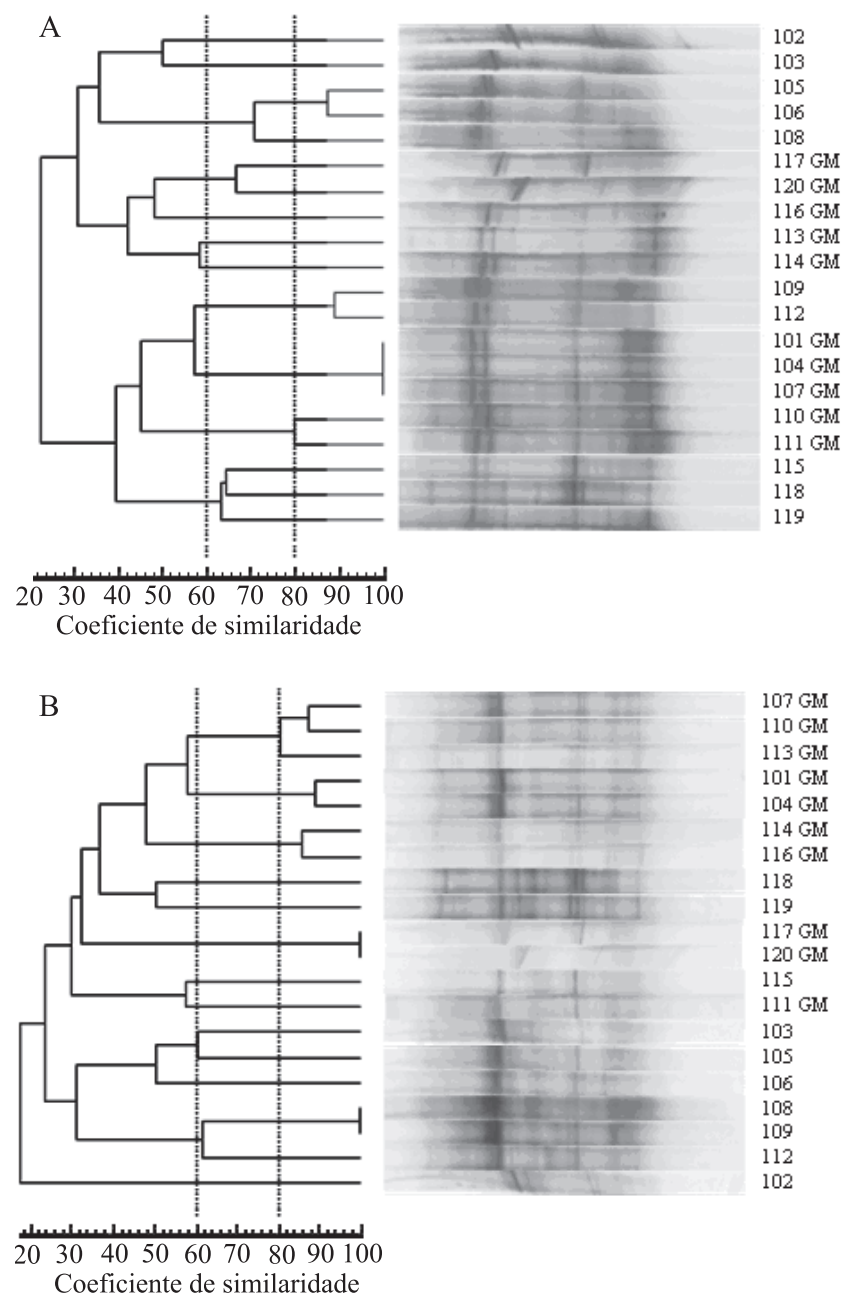

Figura 3. Agrupamentos das amostras obtidas por $16 \mathrm{~S}$ rDNA PCR-DGGE para o subgrupo alfa $(\alpha)$ do filo Proteobacteria a partir de amostras da rizosfera de plantas convencionais (número de parcela sem letra) e geneticamente modificadas (número de parcela seguido pela letra GM). A, primeira coleta, estádio V4 (26 DAP); B, segunda coleta, estádio R6 (40 DAP). Dendrogramas gerados pelo programa GelCompar II, com o coeficiente de Jaccard e o método UPGMA. 
Os perfis obtidos de células rizosféricas não cultiváveis apresentaram os maiores efeitos de separação entre a variedade Olathe Pinto e o evento elite Olathe M1-4 a 60\% de similaridade, na primeira coleta (estádio V4), em que os sete grupos formados apresentavam três grupos exclusivos de amostras obtidas de feijoeiro geneticamente modificado, dois grupos exclusivos de amostras obtidas de feijoeiros da variedade Olathe Pinto e dois grupos mistos (geneticamente modificados e convencionais) (Figura 1 A e B, Tabela 1). Entretanto, houve diminuição dos agrupamentos formados na segunda coleta em estádio R6, com menor separação entre plantas geneticamente modificadas e convencionais e o surgimento de mais agrupamentos mistos (Figura 1 B e C, Tabela 2). Isso não aconteceu para as amostras obtidas por cultivo (Tabela 1 e 2), contrariando o observado por Diepeningen et al. (2005), que encontraram as mesmas tendências nas duas formas de obtenção de amostras. Edenborn \& Sexstone (2007) consideraram que as duas formas de obtenção de células se complementam, após a obtenção de bandas exclusivas nos perfis de DGGE para as frações cultivadas e não cultivadas de bactérias do solo.

Em todas as formas de obtenção de amostras da comunidade bacteriana e períodos de coleta, a maioria das amostras não manteve os mesmos agrupamentos formados (Figuras 1 a 3). Essas variações podem sugerir maior influência de

Tabela 1. Grupos formados com valores de similaridade (S) igual ou superior a 60 e $80 \%$ na primeira coleta (26 dias após o plantio, estádio V4 do feijoeiro), em diferentes fontes de amostras da comunidade bacteriana.

\begin{tabular}{lcccccc}
\hline Fonte das amostras & S & $\begin{array}{c}\text { Grupos } \\
\text { de }\end{array}$ & $\begin{array}{c}\text { Percentagem } \\
\text { amostras }\end{array}$ & GM $^{(2)}$ & C & GMC \\
\hline Bactérias rizosféricas não & 60 & 7 & 90 & 3 & 2 & 2 \\
cultiváveis & 80 & 3 & 30 & 1 & 1 & 1 \\
\hline Bactérias rizosféricas & 60 & 2 & 20 & 1 & 1 & 0 \\
cultivadas em meio KB & 80 & 0 & 0 & 0 & 0 & 0 \\
\hline Bactérias rizosféricas & 60 & 5 & 50 & 1 & 2 & 2 \\
cultivadas em meio TY & 80 & 2 & 20 & 0 & 1 & 1 \\
\hline Bactérias não rizosféricas & 60 & 6 & 65 & 1 & 1 & 4 \\
solo não rizosférico) & 80 & 0 & 0 & 0 & 0 & 0 \\
\hline Alfa-proteobactérias não & 60 & 6 & 75 & 3 & 3 & 0 \\
cultiváveis & 80 & 4 & 45 & 2 & 2 & 0 \\
\hline
\end{tabular}

(1)Percentagem de amostras, percentual de amostras totais agrupadas nas faixas de similaridade indicadas. ${ }^{(2)} \mathrm{GM}, \mathrm{C}$ e GMC, grupos de amostras obtidas de feijoeiro geneticamente modificado (Olathe M1-4), convencional (Olathe Pinto) e grupos mistos geneticamente modificados e convencionais, respectivamente. mudanças fisiológicas inerentes aos estádios de desenvolvimento das plantas sobre a composição da comunidade bacteriana do que do transgene, assim como encontrado por Ferreira et al. (2008) em estudo com batatas. Schmalenberger \& Tebbe (2002) observaram, em experimento com milho geneticamente modificado para a resistência a um herbicida cujo ingrediente ativo era o glufosinato, a diferenciação entre estádios nos perfis gerados a partir das amostras bacterianas obtidas diretamente da rizosfera.

Entre as amostras da comunidade rizosférica (Figura 1) e não rizosférica (Figura 2), foi observada maior complexidade de bandas nos perfis obtidos de solo que naqueles de amostras obtidas da rizosfera, além de distinção entre o período de coleta e a intensidade de obtenção de agrupamentos. As amostras da comunidade rizosférica na primeira e segunda coletas foram representadas com $90 \%$ de participação nos agrupamentos na menor faixa de similaridade avaliada ( $\mathrm{S}=60$ ) e com $30 \%$ na maior $(\mathrm{S}=80)$, enquanto as amostras da comunidade não rizosférica só foram representadas na menor faixa de similaridade $(\mathrm{S}=60)$, com $65 \%$ de participação na primeira coleta e $80 \%$ na segunda (Tabelas 1 e 2). Essa diferença pode ser causada pelo efeito seletivo da rizosfera, já relatado por outros autores (Costa et al., 2000; Gomes et al., 2001; Milling et al., 2004), sem, com isso, descartar a possibilidade de variação em função do emprego de métodos distintos para

Tabela 2. Grupos formados com valores de similaridade (S) igual ou superior a 60 e $80 \%$ na segunda coleta (40 dias após o plantio, estádio R6 do feijoeiro), em diferentes fontes de amostras da comunidade bacteriana.

\begin{tabular}{lcccccc}
\hline Fonte das amostras & $\mathrm{S}$ & $\begin{array}{c}\text { Grupos } \\
\text { Percentagem } \\
\text { de } \text { amostras }^{(1)}\end{array}$ & $\mathrm{GM}^{(2)} \mathrm{C}$ & $\mathrm{GMC}$ \\
\hline Bactérias rizosféricas não & 60 & 6 & 90 & 2 & 1 & 3 \\
cultiváveis & 80 & 3 & 30 & 1 & 2 & 0 \\
\hline Bactérias rizosféricas & 60 & 5 & 65 & 2 & 2 & 1 \\
cultivadas em meio KB & 80 & 2 & 25 & 0 & 2 & 0 \\
\hline Bactérias rizosféricas & 60 & 3 & 40 & 0 & 1 & 2 \\
cultivadas em meio TY & 80 & 0 & 0 & 0 & 0 & 0 \\
\hline Bactérias não rizosféricas & 60 & 8 & 80 & 4 & 4 & 0 \\
(solo não rizosférico) & 80 & 0 & 0 & 0 & 0 & 0 \\
\hline Alfa-proteobactérias não & 60 & 6 & 70 & 4 & 2 & 0 \\
cultiváveis & 80 & 5 & 55 & 4 & 1 & 0 \\
\hline
\end{tabular}

(1)Percentagem de amostras, percentual de amostras totais agrupadas nas faixas de similaridade indicadas. ${ }^{(2)} \mathrm{GM}, \mathrm{C}$ e GMC, grupos de amostras obtidas de feijoeiro geneticamente modificado (Olathe M1-4), convencional (Olathe Pinto) e grupos mistos geneticamente modificados e convencionais, respectivamente. 
a obtenção de células da rizosfera e do solo não rizosférico.

As amostras da comunidade bacteriana do solo não rizosférico não apresentaram separação entre os tratamentos na primeira coleta, no estádio V4, (Figura 2 A). Na segunda coleta, no estádio R6, houve agrupamento separando amostras de plantas geneticamente modificadas das convencionais (Figura 2 B). Adiferença observada nos agrupamentos para estádios de desenvolvimento distintos pode estar relacionada à dinâmica dos microrganismos entre os locais de amostragem e entre formas distintas de obtenção do DNA, como também às variações de temperatura e precipitação pluviométrica.

Os agrupamentos das amostras provenientes de solo não rizosférico indicaram efeitos mais evidentes na separação entre amostras de plantas geneticamente modificadas e convencionais no estádio R6, na segunda coleta (Figura 2 C e D). Wei et al. (2006) verificaram que a influência do organismo geneticamente modificado sobre propriedades químicas do solo, atividade enzimática e comunidade bacteriana sob cultivo foi evidente em mamão resistente à mancha-anelar, ao contrário de Shen et al. (2006), que não constataram efeitos para algodão $\mathrm{Bt}$, o que evidencia que cada evento de transgenia deve ser particularizado nas análises, para evitar generalizações prejudiciais à observação ou não do efeito sobre organismos não alvo. Assim, o monitoramento constante ao longo do ciclo de cultivo de plantas geneticamente modificadas é necessário para verificar se as alterações ocorridas na comunidade microbiana da rizosfera e do solo são mantidas ao longo dos ciclos da planta.

Nos perfis de $16 \mathrm{~S}$ rDNA PCR-DGGE obtidos para o subgrupo alfa $(\alpha)$ do filo Proteobacteria, foi observada a formação de grupos exclusivos nas duas coletas, comalta representaçãopercentual de amostras agrupadas tanto para similaridade igual ou superior a $60 \%$ quanto para similaridade igual ou superior a $80 \%$, sem, contudo, manter os agrupamentos como observado anteriormente (Tabelas 1 e 2 e Figura 3). Segundo Heuer et al. (2002), a amplificação de grupos específicos aumenta a sensibilidade da análise por DGGE. Em outro estudo, que avaliou o efeito da solarização sobre a comunidade bacteriana, foi observada distinção mais evidente entre o solo solarizado e não solarizado quando se analisaram os perfis de DGGE do subgrupo alfa $(\alpha)$ do filo Proteobacteria (Gelsomino \& Cacco, 2006). Porém, outros autores, ao comparar plantas transgênicas, observaram a mesma tendência entre os perfis de comunidade bacteriana total e grupos específicos, como alfa e beta, de Proteobacteria, actinomicetos e Pseudomonas (Heuer et al., 2002; Milling et al., 2004).

Segundo Bruinsma et al. (2003), diversos estudos que avaliam o efeito de plantas geneticamente modificadas sobre microrganismos com técnicas distintas detectaram variações ou tendências diferentes em extensão e intensidade sem, entretanto, serem capazes de demonstrar efeito significativo dos transgenes. Outros estudos demostraram efeitos transitórios e temporários da atividade enzimática no solo e da estrutura bacteriana associada à rizosfera (Rasche et al., 2006), ou efeitos variáveis entre os estágios de desenvolvimento da planta, como demonstrado para estrutura de perfis da comunidade bacteriana por Schmalenberger \& Tebbe (2002) e Milling et al. (2004).

Os dados obtidos neste trabalho, com a técnica do 16S rDNAPCR-DGGE, complementam a informação existente na literatura relacionada aos efeitos da transgenia sobre a comunidade bacteriana, segundo a qual a comparação entre a comunidade bacteriana associada às plantas geneticamente modificadas (evento elite Olathe M1-4) e às plantas do genótipo de origem (Olathe Pinto) permitiu a observação de alterações na comunidade bacteriana. A importância e o impacto dessas alterações devem ser avaliados visando maior compreensão dos efeitos do transgene relacionados com os aspectos funcionais da biota do solo associada.

\section{Conclusões}

1. Os agrupamentos obtidos dos perfis de 16S rDNA PCR-DGGE indicam alterações na comunidade bacteriana associada às raízes das plantas geneticamente modificadas (evento elite Olathe M1-4) em comparação às associadas às plantas convencionais (Olathe Pinto).

2. A origem das amostras, obtidas de células cultivadas ou não cultivadas, e o estádio de desenvolvimento da planta afetam os perfis da comunidade bacteriana obtidos por meio de perfis de 16S rDNA PCR-DGGE. 


\section{Agradecimentos}

À Coordenação de Aperfeiçoamento de Pessoal de Nível Superior e à Financiadora de Estudos e Projetos, pelo suporte financeiro.

\section{Referências}

ARAGÃO, F.J.L.; VIANNA, G.R.; ALBINO, M. das M.C.; DIAS, B.B.A.; FARIA, J.C. Transgênico resistente a geminivírus. Biotecnologia Ciência \& Desenvolvimento, v.3, p.22-26, 2001.

BONFIM, K.; FARIA, J.C.; NOGUEIRA, E.O.P.L.; MENDES, E.A.; ARAGÃO, F.J.L. RNAi-mediated resistance to bean golden mosaic virus in genetically engineered common bean (Phaseolus vulgaris). Molecular Plant-Microbe Interactions, v.20, p.717-726, 2007.

BRUINSMA, M.; KOWALCHUK, G.A.; VEEN, J.A. van. Effects of genetically modified plants on microbial communities and processes in soil. Biology and Fertility of Soils, v.37, p.329-337, 2003.

COSTA, J.G.C. da; VIEIRA, N.R. de A. Qualidade, classificação comercial e manejo pós-colheita. In: YOKOYAMA, L.P.; STONE, L.F. (Ed.). Cultura do feijoeiro no Brasil: características da produção. Santo Antônio de Goiás: Embrapa Arroz e Feijão, 2000. 75p.

CRESTE, S.; NETO,A.T.; FIGUEIRA,A. Detection of single sequence repeat polymorphisms in denaturing polyacrylamide sequencing gels by silver staining. Plant Molecular Biology Reporter, v.19, p.299-306, 2001.

DIEPENINGEN, A.D. van; VOS, O.J. de; ZELENEV, V.V.; SEMENOV, A.M.; BRUGGEN, A.H.C. van. DGGE fragments oscillate with or counter to fluctuations in cultivable bacteria along wheat roots. Microbial Ecology, v.50, p.506-517, 2005.

DÖBEREINER, J.; ANDRADE, V. de O.; BALDANI, V.L.D. Protocolos para preparo de meios de cultura da Embrapa Agrobiologia. Seropédica: Embrapa-CNPAB, 1999. 38p. (Embrapa-CNPAB. Documentos, 110).

EDENBORN, S.L.; SEXSTONE, A.J. DGGE fingerprinting of culturable soilbacterial communities complements culture-independent analyses. Soil Biology \& Biochemistry, v.39, p.1570-1579, 2007.

FARIA, J.C.; ALBINO, M.M.C.; DIAS, B.B.A.; CANÇADO, L.J.; CUNHA, N.B. da; SILVA, L. de M.; VIANNA, G.R.; ARAGÃO, F.J.L. Partial resistance to Bean golden mosaic virus in a transgenic common bean (Phaseolus vulgaris L.) line expressing a mutated rep gene. Plant Science, v.171, p.565-571, 2006.

FERNÁNDEZ, F.; GEPTS, P.; LÓPES, M. Etapas de desarrollo de la planta de frijol (Phaseolus vulgaris L.). Cali: Centro Internacional de Agricultura Tropical, 1986. 34p.

FERREIRA, E.P. de B.; DUSI, A.N.; COSTA, J.R.; XAVIER, G.R.; RUMJANEK, N.G. Assessing insecticide and fungicide effects on the culturable soil bacterial community by analyses of variance of their DGGE fingerprinting data. European Journal of Soil Biology, v.45, p.466-472, 2009.

FERREIRA, E.P. de B.; DUSI, A.N.; XAVIER, G.R.; RUMJANEK, N.G. Rhizosphere bacterial communities of potato cultivars evaluated through PCR-DGGE profiles. Pesquisa Agropecuária Brasileira, v.43, p.605-612, 2008.
GEELS, F.P.; SCHIPPERS, B. Reduction of yield depression in high-frequency potato cropping soil after seed tuber treatments with antagonistic fluorescent Pseudomonas spp. Journal of Phytopathology, v.108, p.207-214, 1983.

GELSOMINO, A.; CACCO, G. Compositional shifts of bacterial groups in a solarized and amended soil as determined by denaturing gradient gel electrophoresis. Soil Biology \& Biochemistry, v.38, p.91-102, 2006.

GELSOMINO,A.; KEIJZER-WOLTERS,A.C.; CACCO, G.; ELSAS, J.D. van. Assessment of bacterial community structure in soil by polymerase chain reaction and denaturing gradient gel electrophoresis. Journal of Microbiological Methods, v.38, p.1-15, 1999.

GOMES, N.C.M.; HEUER, H.; SCHONFELD, J.; COSTA, R.; MENDONÇA-HAGLER, L.; SMALLA, K. Bacterial diversity of the rhizosphere of maize (Zea mays) grown in tropical soil studied by temperature gradient gel electrophoresis. Plant and Soil, v.232, p.167-180, 2001.

HEUER, H.; KROPPENSTEDT, R.M.; LOTTMANN, J.; BERG, G., SMALLA, K. Effects of T4 lysozyme release from transgenic potato roots on bacterial rhizosphere relative to communities are negligible relative to natural factors. Applied and Environmental Microbiology, v.68, p.1325-1335, 2002.

MILLING, A.; SMALLA, K.; MAIDL, F.X.; SCHLOTER, M.; MUNCH, J.C. Effects of transgenic potatoes with an altered starch composition on the diversity of soil and rhizosphere bacteria and fungi. Plant and Soil, v.266, p.23-39, 2004.

NÜBEL, U.; ENGELEN, B.; FELSKE, A.; SNAIDR, J.; WIESHUBER, A.; AMANN, R.I.; LUDWIG, W.; BACKHAUS, I. Sequence heterogeneities of genes encoding $16 \mathrm{~S}$ rRNAs in Paenibacillus polymyxa detected by temperature gradient gel electrophoresis. Journal of Bacteriology, v.178, p.5636-5643, 1996.

ORIANI, M.A.G. Resistência de genótipos de feijoeiro portadores de arcelina a Bemisia argentifolii (Bellows \& Perring) (Homoptera: Aleyrodidae) e ao vírus do mosaico dourado. 1998. 107p. Tese (Doutorado) - Universidade Estadual Paulista, Jaboticabal.

RASCHE, F.; HÖDL, V.; POLL, C.; KANDELER, E.; GERZABEK, M.H.; ELSAS, J.D. van; SESSITSCH, A. Rhizosphere bacteria affected by transgenic potatoes with antibacterial activities compared with the effects of soil, wild-type potatoes, vegetation stage and pathogen exposure. FEMS Microbiology Ecology, v.56, p.219-235, 2006.

SCHMALENBERGER, A.; TEBBE, C.C. Bacterial community composition in the rhizosphere of a transgenic, herbicide-resistant maize (Zea mays) and comparison to its non-transgenic cultivar Bosphore. FEMS Microbiology Ecology, v.40, p.29-37, 2002.

SHEN, R.F.; CAI, H.; GONG, W.H. Transgenic Bt cotton has no apparent effect on enzymatic activities or functional diversity of microbial communities in rhizosphere soil. Plant and Soil, v.285, p.149-159, 2006.

STANSLY,P.A.;SANCHEZ,P.A.;RODRIGUEZ,J.M.;CAÑIZARES, F.; NIETO, A.; LEYVA, M.J.L.; FAJARDO, M.; SUÁREZ, V.; URBANEJA, A. Prospects for biological control of Bemisia tabaci (Homoptera, Aleyrodidae) in greenhouse tomatoes of southern Spain. Crop Protection, v.23, p.701-712, 2004. 
TORRES, J.B.; SILVA-TORRES, C.S.A. da. Interação entre inseticidas e umidade do solo no controle do pulgão e da mosca-branca em algodoeiro. Pesquisa Agropecuária Brasileira, v.43, p.949-956, 2008.

WASAKI, J.; ROTHE, A.; KANIA, A.; NEUMANN, G.; RÖMHELD, V.; SHINANO, T.; OSAKI, M., KANDELER, E. Root exudation, phosphorus acquisition, and microbial diversity in the rhizosphere of white lupine as affected by phosphorus supply and atmospheric carbon dioxide concentration. Journal of Environmental Quality, v.34, p.2157-2166, 2005.

WEI, X.D.; ZOU, H.L.; CHU, L.M.; LIAO, B.; YE, C.M.; LAN, C.Y. Field released transgenic papaya affects microbial communities and enzyme activities in soil. Plant and Soil, v.285, p.347-358, 2006.
WEISBURG, W.G.; BARNS, S.M.; PELLETIER, D.A.; LANE, D.J. $16 \mathrm{~S}$ ribossomal DNA amplification for phylogenetic study. Journal of Bacteriology, v.173, p.697-703, 1991.

XAVIER, G.R.; SILVA, F.V.; ZILLI, J.E.; RUMJANEK, N.G. Adaptação de método para extração de DNA microbiano. Seropédica: Embrapa Agrobiologia, 2004. 24p. (Embrapa Agrobiologia. Documentos, 171).

ZILLI, J.É.; BOTELHO, G.R.; NEVES, M.C.P.; RUMJANEK, N.G. Efeito de glyphosate e imazaquin na comunidade bacteriana do rizoplano de soja (Glycine $\max$ (L.) Merrill) e em características microbiológicas do solo. Revista Brasileira de Ciência do Solo, v.32, p.633-642, 2008.

Recebido em 2 de setembro de 2009 e aprovado em 15 de novembro de 2009 